\title{
Characterization of hLF1-11 immobilization onto chitosan ultrathin films, and its effects on antimicrobial activity
}

\author{
Fabíola Costa $^{\mathrm{a}, \mathrm{b}}$, Sílvia Maia ${ }^{\mathrm{c}}$, Joana Gomes ${ }^{\mathrm{a}}$, Paula Gomes ${ }^{\mathrm{c}, 1}$, M. Cristina L. Martins ${ }^{\mathrm{a}, \mathrm{d}, *, 1}$ \\ a INEB - Instituto de Engenharia Biomédica, Universidade do Porto, Rua do Campo Alegre, 823, 4150-180 Porto, Portugal \\ ${ }^{\mathrm{b}}$ Universidade do Porto, Faculdade de Engenharia, Porto, Portugal \\ 'Universidade do Porto, CIQ-UP - Departamento de Química e Bioquímica, Faculdade de Ciências, Porto, Portugal \\ ${ }^{\mathrm{d}}$ Universidade do Porto, Instituto de Ciências Biomédicas Abel Salazar, Porto, Portugal
}

\section{A R T I C L E I N F O}

\section{Article history:}

Received 25 July 2013

Received in revised form 3 February 2014

Accepted 17 February 2014

Available online 12 March 2014

\section{Keywords:}

Antimicrobial peptides (AMP)

Surface immobilization

Surface characterization

Bacterial adhesion

Chitosan

\begin{abstract}
A B S T R A C T
hLF1-11 (GRRRRSVQWCA) is an antimicrobial peptide (AMP) with high activity against methicillin-resistant Staphylococcus aureus (MRSA), the most prevalent species in implant-associated infection. In this work, the effect of the surface immobilization on hLF1-11 antimicrobial activity was studied. Immobilization was performed onto chitosan thin films as a model for an implant coating due to its reported osteogenic and antibacterial properties. Chitosan thin films were produced by spin-coating on gold surfaces. hLF1-11 was immobilized onto these films by its C-terminal cysteine in an orientation that exposes the antimicrobial activity-related arginine-rich portion of the peptide. Two levels of exposure (with and without a polyethylene glycol (PEG) spacer) were analyzed. Covalent immobilization was further compared with the AMP physical adsorption onto chitosan films. Surfaces were characterized using ellipsometry, contact angle measurements, atomic force microscopy, infrared and X-ray photoelectron spectroscopies and using a fluorimetric assay for hLF1-11 quantification. Surface antimicrobial activity was assessed through surface adhesion and viability assays using an MRSA (S. aureus ATCC 33591). The incorporation of hLF1-11 increased significantly bacterial adhesion to chitosan films. However, the presence of hLF1-11, namely when immobilized through a PEG spacer, decreased the viability of adherent bacteria with regard to the control surface. These results demonstrated that hLF1-11 after covalent immobilization by its cysteine can maintain activity, particularly if a spacer is applied. However, further studies, exploring the opposite orientation or the same C-terminal orientation, but non-cysteine related, can help to clarify the potential of the hLF1-11 immobilization strategy.
\end{abstract}

( 2014 Acta Materialia Inc. Published by Elsevier Ltd. All rights reserved.

\section{Introduction}

Antimicrobial peptides (AMPs) are a new class of antibiotics with very promising characteristics. They are usually composed of short sequences of amino acids ( $<50$ residues), with simultaneous amphipathic and cationic behaviors [1]. Although the AMPs' exact mechanism of action is not fully elucidated, it is generally accepted to include electrostatic interactions between the bacterium negatively charged outer layer and the positively charged AMP, which results in bacterial death $[1,2]$. Their most interesting features are: high activity against a broad spectrum of microorganisms (Gram-positive and -negative bacteria, yeasts), high selectiv-

\footnotetext{
* Corresponding author at: Instituto de Engenharia Biomédica (INEB), Rua do Campo Alegre, 823, 4150-180 Porto, Portugal. Tel.: +351 226074982.

E-mail address: cmartins@ineb.up.pt (M.C.L. Martins).

1 These authors contributed equally to this work.
}

ity towards microorganisms and not mammalian cells (which have zwitterionic membranes), fast killing even at low concentrations and, most importantly, they do not have the tendency to induce resistance $[1,3]$. This last feature differentiates them from the classical antibiotics presently used. However, AMP application has some associated challenges, namely (i) proteolytic degradation, (ii) peptide co-precipitation with plasma carrier proteins and (iii) peptide self-aggregation. Also, if higher titers are applied to circumvent such problems, cytotoxic effects become apparent. One current strategy to overcome these challenges is its covalent immobilization onto a surface [4].

In the present work we have chosen hLF1-11, which is a 11-mer derived from human Lactoferrin. This amphipathic peptide, with an hydrophilic $\mathrm{N}$-terminal and a hydrophobic $\mathrm{C}$-terminal, has a wide spectrum of activity, associated with an excellent safety profile, tested both in vitro and in vivo [5-7]. Indeed, it has been tested against methicillin-resistant Staphylococcus aureus (MRSA) in an osteomyelitis model [8-10]. However, in this model, the delivery 
system consisted of hLF1-11 incorporated in calcium phosphate (Ca-P) cement, which resulted in burst peptide release only [11]. Likewise, Kazemzadeh-Narbat et al. [12] tested hLF1-11 on a $\mathrm{Ca}-\mathrm{P}$ microporous coating and found the peptide to have a slow and incompetent release. Therefore, as the soluble hLF1-11 application has not provided sufficient activity, we decided to test whether covalent immobilization could originate an efficient antimicrobial coating against implant-related infections. To this end, we needed a polymer that would be easily functionalized, but also would have intrinsic characteristics favorable to the product end application, as allowing osteointegration, and inhibiting bacterial adhesion and growth. Therefore, we chose chitosan, as it fulfills the characteristics mentioned above, with reported antimicrobial [13-16] and osteogenic properties [17-20]. As summarized by us [4], AMP covalent immobilization may result in activity lost, so some parameters should be addressed in order to obtain maximum activity, namely (i) orientation ( $N$ - or $C$-terminal immobilization) and (ii) exposition. The combination of these parameters gives rise to different immobilization profiles that can have very distinct activities. Some papers have reported that positively charged amino acids (arginine) of its $N$-terminal are essential for hLF1-11 antimicrobial activity $[6,7,21]$. Also, the natural sequence of hLF1-11 offers a free sulfhydryl group at the cysteine residue near the $C$-terminal, which can be used for disulfide bridge establishment with SH-modified chitosan. This is a simple, mild reaction that allows the control of peptide orientation. Therefore in this study, we immobilize hLF1-11 by its $C$-terminal (exposing the arginine/ positive end) directly to the polymer (for a more strict and oriented exposition of the AMP) or through a spacer (for a more movable/ flexible exposition) and compare its activity against simple physical adsorption of the peptide onto the polymer.

\section{Materials and methods}

\section{1. hLF1-11 synthesis and characterization}

hLF1-11 (GRRRRSVQWCA, C-terminal amide) was produced by Fmoc/tBu solid-phase peptide synthesis methodologies assisted with microwave energy (Liberty 1 Microwave Peptide Synthesizer, CEM Corporation) $[22,23]$. Crude product was purified by reversephase liquid chromatography and confirmed by high-performance liquid chromatography (Hitachi-Merck LaChrom Elite), liquid chromatography-electrospray ionization mass spectrometry (LCQ-DecaXP LC-MS system, ThermoFinnigan) and ultraviolet spectrometry. The peptide used presented a purity level higher than $90 \%$.

\section{2. $h L F 1-11$ surface immobilization}

\subsubsection{Substrate preparation}

$\mathrm{Au}$ production and cleaning were performed according to Martins et al. [29]. Briefly, chromium (5 nm) and gold (25 nm) layers were deposited by ion beam sputtering from chromium and gold targets (99.9\% purity) on silicon wafers (AUREL, GmbH). Chromium was used to improve the adhesion of gold to silicon. Gold substrates were cleaned with "piranha" solution ( 7 parts of $\mathrm{H}_{2} \mathrm{SO}_{4}$ and 3 parts of $30 \% \mathrm{H}_{2} \mathrm{O}_{2}$ ) for 5 min (caution: this solution reacts violently with many organic materials and should be handled with suitable protective measures), thoroughly rinsed with ethanol and dried with a gentle stream of argon.

\subsubsection{Preparation of chitosan ultrathin films}

Commercial squid pen chitosan (France Chitine) was purified by the reprecipitation method [25]. Chitosan thin films were prepared by dispensing a drop of chitosan solution $(0.4 \%$ in acetic acid $\mathrm{w} / \mathrm{v})$ [26] on the center of the Au substrates $\left(150 \mu \mathrm{l}\right.$ for $1 \times 1 \mathrm{~cm}^{2}$ sub- strates) placed in the spin coater equipment (Laurell Technologies Corporation) and spun at $9000 \mathrm{rpm}$ for $1 \mathrm{~min}$. Then, the newly prepared ultrathin films were neutralized with $0.1 \mathrm{M} \mathrm{NaOH}$ for $5 \mathrm{~min}$ and rinsed twice with MilliQ water. Each sample was dried with a gentle stream of argon and stored in sealed plastic Petri dishes saturated with argon until use.

\subsection{Peptide immobilization}

hLF1-11 immobilization on chitosan thin films was performed by forming a persulfate bond (disulfide bridge) between free sulfhydryl groups present in the peptides cysteine side chain and in pre-functionalized chitosan (Fig. 1).

\subsubsection{Introduction of $\mathrm{SH}$ groups onto chitosan films}

Functionalization of chitosan thin films with $\mathrm{SH}$ groups was obtained by the coupling of N-acetyl cysteine (NAC) (Merck), or O-(2-carboxyethyl)-o'-(2-mercaptoethyl) heptaethylene glycol (Sp) (Sigma Aldrich $\geqslant 95 \%$ purity). Chitosan thin films were treated with a solution of $0.2 \mathrm{M}$ 1-ethyl-3-(3-dimethylaminopropyl)carbodiimidehydrochloride) (EDC; Sigma-Aldrich), 0.05 M N-hydroxysulfosuccimide (NHS; Sigma-Aldrich) and $25 \mathrm{mM}$ of SH agent (NAC or $\mathrm{Sp}$ ) in $0.1 \mathrm{M}$ ( $N$-morpholino)ethanesulfonic acid (MES; Sigma-Aldrich) buffer at $\mathrm{pH} 6.5$ for $1 \mathrm{~h}$ (NAC) or $2 \mathrm{~h} \mathrm{(Sp),} \mathrm{at} 37^{\circ} \mathrm{C}$ and $100 \mathrm{rpm}$. Samples were then rinsed with MilliQ water, immersed for $1 \mathrm{~min}$ in an ultrasound bath (Bandelin Sonorex Digitec Bath $35 \mathrm{kHz}$ ) and rinsed again with MilliQ water.

\subsubsection{Peptide chemical and physical immobilization}

Non-modified (for simple physical adsoption) and modified chitosan substrates were incubated with $1 \mathrm{mg} \mathrm{ml}^{-1}$ peptide solution in $10 \mathrm{mM}$ TrisHCl, $\mathrm{pH} 8.0$, in oxidative conditions $(20 \%$ dimethyl sulfoxide (DMSO)) for $18 \mathrm{~h}$, at $30^{\circ} \mathrm{C}$ and $120 \mathrm{rpm}$.

\subsection{Surface characterization}

\subsubsection{Infrared reflection absorption spectroscopy (IRRAS)}

Measurements were performed on a Perkin Elmer Fourier transform infrared spectrophotometer, model 2000, coupled to a VeeMax II Accessory (PIKE) and a liquid-nitrogen-cooled mercury cadmium telluride (MCT) detector. In order to ensure that there was no water vapor adsorption, dry nitrogen was purged into the instrument for 5 min before and during the measurement of each sample. For each substrate, a similar gold surface was used as a background. Incident light was p-polarized and spectra were collected using the $80^{\circ}$ grazing angle reflection mode. For each sample, 100 scans were collected with $4 \mathrm{~cm}^{-1}$ resolution.

\subsubsection{Ellipsometry}

Ellipsometry measurements were performed using an imaging ellipsometer, model $\mathrm{EP}^{3}$, from Nanofilm Surface Analysis. This ellipsometer was operated in a polarizer-compensatorsample-analyzer mode (null ellipsometry). The light source was a solid-state laser with a wavelength of $532 \mathrm{~nm}$. The gold substrate refractive index $(n=0.6244)$ and extinction coefficient $(k=2.3845)$ were determined using a delta and psi spectrum with a variation of angle between 65 and $71^{\circ}$. These measurements were made in four zones to correct for any instrument misalignment. The thickness of the chitosan films was determined using $(n)$ chitosan $=1.54$ and $(k)$ chitosan $=0$ [27]. Results are presented as the average of three measurements on each of two samples.

\subsubsection{X-ray photoelectron spectroscopy (XPS)}

XPS measurements were carried out on a VG Scientific Escalab $200 \mathrm{~A}$ (UK) spectrometer using magnesium $K_{\alpha}(1253.6 \mathrm{eV})$ as the radiation source (from CEMUP - Centro de Materiais da 


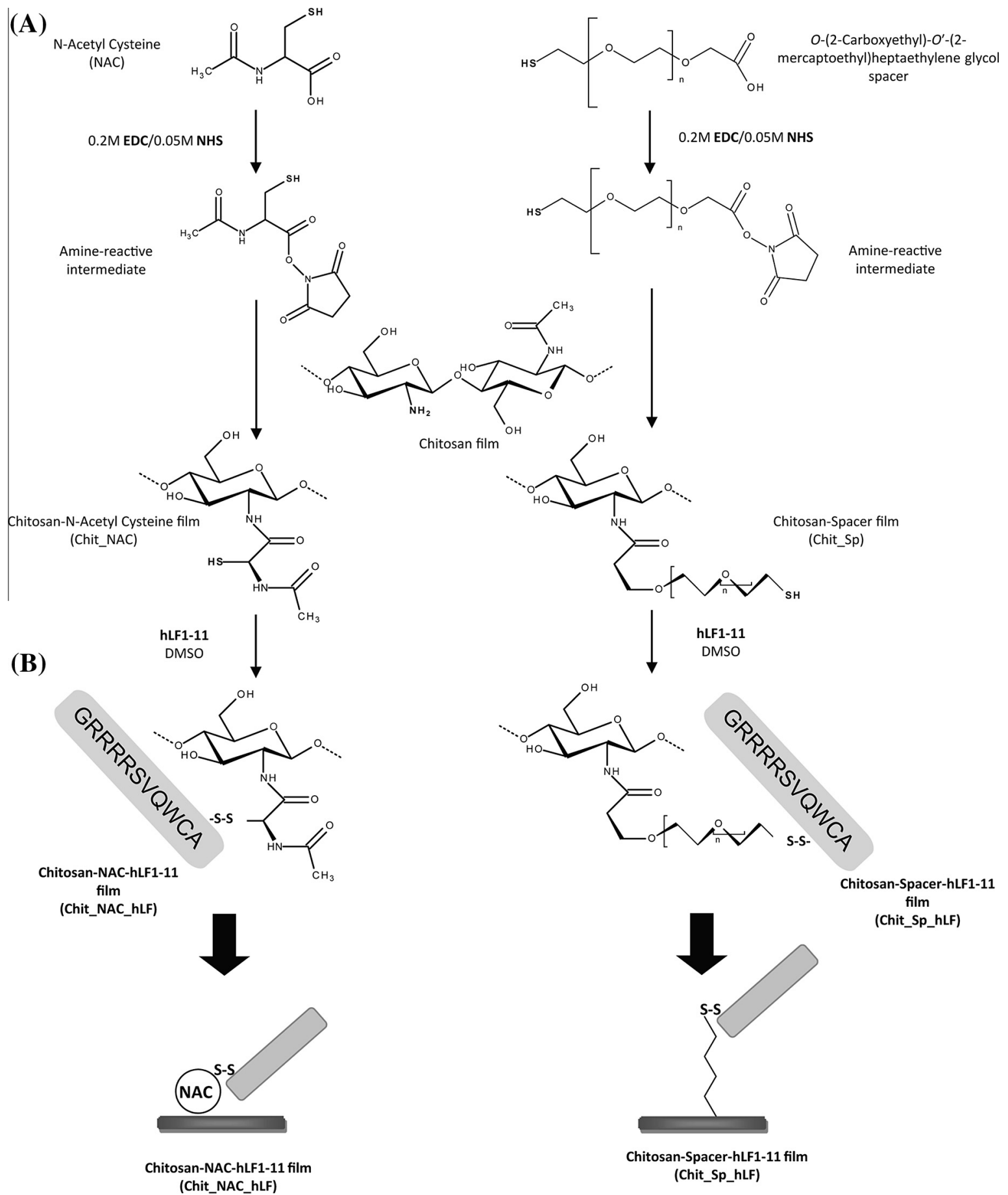

Fig. 1. (A) Chitosan modification with NAC or Sp; (B) hLF1-11 immobilization by establishment of a covalent disulfide bridge.

Universidade do Porto). The photoelectrons were analyzed at a take-off angle of $55^{\circ}$. Survey spectra were collected over a range of $0-1150 \mathrm{eV}$ with an analyzer pass energy of $50 \mathrm{eV}$. High-resolution $\mathrm{C} 1 s, \mathrm{O} 1 s, \mathrm{~N} 1 s, \mathrm{~S} 2 p$ and Au4 $f$ spectra were collected with an analyzer pass energy of $20 \mathrm{eV}$. The binding energy (BE) scales were referenced by setting the $\mathrm{C} 1 \mathrm{~s} \mathrm{BE}$ to $285.0 \mathrm{eV}$. All the spectra were fitted using XPS peak fitting software (XPSPEAK Version 4.1). Element atomic percentages were calculated from the integrated intensities of the XPS peaks, taking into account the atomic sensitivity factors of the instrument data system. Sulfur high resolution spectra were fitted with a doublet structure with a 2:1 area ratio and splitting of $1.2 \mathrm{eV}$, as described by Castner et al. [28]. All sulfur spectra were fitted with a $1.7 \mathrm{eV}$ full width at half maximum profile.

\subsubsection{Water contact angle measurements}

Contact angle measurements were performed using the sessile drop method with a contact angle measuring system from Data Physics, model optical contact angle (OCA) 15, equipped with a video CCD camera and SCA 20 software, as described by Martins et al. [29]. After deposition of $4 \mu \mathrm{l}$ drops of MilliQ water, images were taken every 2 s over $300 \mathrm{~s}$. Droplet profiles were fitted using different mathematical functions, to calculate the contact angle. The ellipse fitting method was used to calculate contact angles between $90^{\circ}$ 
and $30^{\circ}$. The water contact angle of each substrate was calculated by extrapolating the time-dependent curve to zero. Results are the average of three measurements on three independent samples.

\subsubsection{Atomic force microscopy (AFM)}

AFM studies were carried out using a PicoPlus scanning probe microscope interfaced with a Picoscan 2500 controller (both from Agilent Technologies, USA). Each sample was imaged with a $10 \times 10 \mu \mathrm{m}^{2}$ piezo-scanner. The surface roughness was determined in $700 \times 700 \mathrm{~nm}^{2}$ scanned areas in five randomly chosen locations per sample, at room temperature. The roughness height parameter calculated was the root mean square roughness, which corresponds to the deviations from the center $x-y$ plane $(R q)$. The center plane is a plane such that the volumes enclosed by the image surface above and below are equal. The control gold substrate was analyzed through Tapping ${ }^{\circledR}$ mode, with a spring constant of $K=1-5 \mathrm{~N} \mathrm{~m}^{-1}$ using a silicon tip. Samples were analyzed in contact mode, using a silicon nitride tip with a spring constant of $K=0.58 \mathrm{~N} \mathrm{~m}^{-1}$.

\subsubsection{Peptide surface density}

Tethered peptide quantification was performed through colorimetric reaction using 9,10-phenanthrenequinone (PHQ, Fluka) [30]. The reaction between PHQ and arginine or arginine residues forms a stable compound which fluoresces upon excitation [30]. Present protocol was adapted from Kazemzadeh-Narbat et al. [12] Substrates were sonicated $1 \mathrm{~h}$ in $0.1 \mathrm{M} \mathrm{HCl}$ in an ultrasound bath. Then, $1 \mathrm{ml}$ of each sample solution was added to $3 \mathrm{ml}$ of $3.5 \mu \mathrm{M}$ PHQ in absolute ethanol. Simultaneously $0.5 \mathrm{ml}$ of $2 \mathrm{M}$ $\mathrm{NaOH}$ was added to adjust the $\mathrm{pH}$. The mixture was then incubated at $30^{\circ} \mathrm{C}$ for $3 \mathrm{~h}$. Finally, $2.25 \mathrm{ml}$ of $2.4 \mathrm{M} \mathrm{HCl}$ was added to stop the reaction. At this point, the characteristic wavelengths were determined from the excitation and emission spectra. The highest emission intensity was found at the wavelength of $380 \mathrm{~nm}$. The highest peak at the excitation spectrum $(256 \mathrm{~nm})$ was chosen for the maximum emission output. The fluorescence emission was measured using a fluorescence microplate reader (Biotek Synergy Mx Luminometer). The amount of hLF1-11 was calculated based on a calibration curve prepared with standard solutions of free L-arginine (Fluka) and free hLF1-11. Standard solutions of free hLF1-11 were adjusted by quantification at $280 \mathrm{~nm}$ in a Thermo Scientific "Nanodrop 1000" spectrophotometer.

\subsection{Bacterial assays}

\subsubsection{Bacterial strains, media and growth conditions}

Methicillin-resistant $S$. aureus Subsp aureus strains (ATCC 33591) were obtained from the American Type Culture Collection. Bacteria were grown on tryptic soya agar (TSA) (Merck) and tryptic soya broth (TSB) (Merck). Bacterial suspensions were adjusted by measuring optical density $(600 \mathrm{~nm})$. Bacterial numbers were confirmed by a colony forming units (CFUs) count.

\subsubsection{Minimal inhibitory concentration determination}

Minimal inhibitory concentration (MIC) was established with a modified broth microdilution method in Mueller Hinton broth (MHB) [31].

\subsubsection{Bacterial-surface interaction}

2.5.3.1. Sample preparation. Test surfaces were washed successively in $70 \%$ ethanol and sterile water, and then dried in sterile environment. Samples were then transferred to a 24-well, flat-bottom cellular suspension plates (Sarstedt, Ltd, Newton, USA).

2.5.3.2. Sample incubation with bacteria. $500 \mu \mathrm{l}$ of $3 \times 10^{7} \mathrm{CFU} \mathrm{ml}^{-1}$ bacterial solution (S. aureus ATCC 33591) was then added to each well and incubated at $37^{\circ} \mathrm{C}$ for $4 \mathrm{~h}$. Surrounding wells were filled with $1 \mathrm{ml}$ of sterilized deionized water, in order to avoid broth evaporation.

2.5.3.3. Non-adherent viable bacteria (supernatant) assay. After the incubation period, serial dilutions of the supernatants were performed and plated onto TSA plates. CFU counts were assessed after $18 \mathrm{~h}$ incubation at $37^{\circ} \mathrm{C}$.

2.5.3.4. Bacterial surface adhesion assay. After the incubation period, substrates were rinsed with phosphate buffered saline (PBS) sterile solution, and then fixed with $300 \mu \mathrm{l}$ of paraformaldehyde $4 \%$ for 20 min. Substrates were rinsed again with sterile PBS solution and stained with VECTASHIELD ${ }^{\circledR}$ Mounting Medium with $\left(4^{\prime}, 6\right.$ diamidino-2-phenylindole (DAPI; Vector). DAPI binds to bacteria DNA, is excited at $\sim 360 \mathrm{~nm}$ and emits at $\sim 460 \mathrm{~nm}$, resulting in blue fluorescence. Images were obtained with an inverted fluorescence microscope (Axiovert $200 \mathrm{M}$, Zeiss, Germany) using a magnification of $1000 \times$, corresponding to a net surface area of $\sim 0.1181 \mathrm{~mm}^{2}$ per sample. For quantifying the total adherent bacteria, eight fields of each sample were obtained and analyzed using ImageJ software. The image analysis results were measured as the average area of cells per field of view, and are reported as the average percentage coverage. Three replicates for each condition were used.

2.5.3.5. Viable surface adherent bacteria assay. After the incubation period, substrates were rinsed with PBS sterile solution to remove non-adherent bacteria, transferred to a new plate with $500 \mu \mathrm{l}$ of PBS and then sonicated for $8 \mathrm{~min}$ in an ultrasound bath (Bandelin Sonorex Digitec Bath $35 \mathrm{kHz}$ ) to release all adherent bacteria. After sonication, serial dilutions of the supernatant were performed, and plated onto TSA. CFU counts were performed after $18 \mathrm{~h}$ of incubation at $37^{\circ} \mathrm{C}$. Three replicates for each condition were used. To control sonication efficiency, the sonicated substrates were stained with VECTASHIELD ${ }^{\circledR}$ Mounting Medium with DAPI and observed using a inverted fluorescence microscopy, to guarantee that all bacteria were removed from the surface. Also, the initial inoculum was plated before and after sonication, to ensure that minimum death was promoted by the technique.

\subsection{Statistical analysis}

For statistical analysis, one-way analysis of variance followed by Tukey's post hoc testing were used. When Gaussian distribution was not confirmed (Antimicrobial activity assays) the nonparametric Kruskal-Wallis test was applied using the Graphpad Prism program. Data are expressed as the mean \pm standard deviation (SD) and $p$ values of $<0.05$ were considered significant.

\section{Results}

\subsection{Surface characterization}

Chitosan thin films with and without hLF1-11 were characterized using ellipsometry, water contact angle measurements, AFM, IRRAS, XPS and fluorimetric assay.

\subsubsection{Ellipsometry}

The thickness of the spin-coated chitosan films was $14.6 \pm 1.4 \mathrm{~nm}$. Films remained stable during reaction procedures, since no thickness differences were detected between freshly and buffer incubated films (data not shown). Fig. 2A shows the thickness of chitosan thin films after surface modification. The thickness 

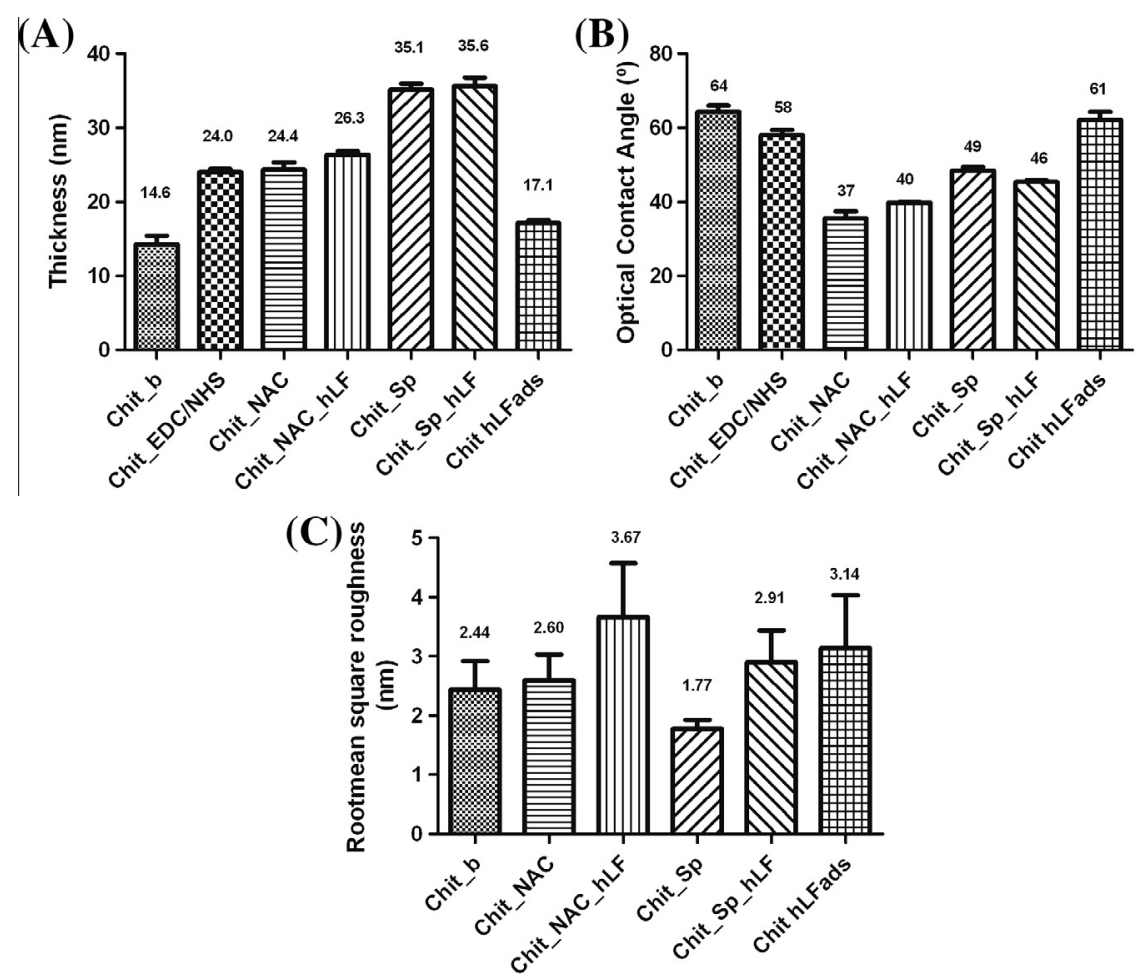

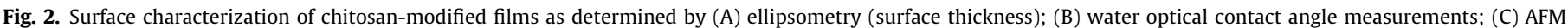
(surface roughness).

of chitosan films increased after its functionalization with NAC $(+9.8 \mathrm{~nm})$ or $\mathrm{Sp}(+20.5 \mathrm{~nm})(p<0.05)$, which is proportional to the length of the immobilized structure, suggesting the success of the functionalization. After hLF1-11 immobilization onto Chit_NAC (Chit_NAC_hLF), a $2 \mathrm{~nm}$ thickness increase was observed $(p<0.05)$, indicating that the peptide was successfully bonded to the polymer. However, hLF1-11 immobilization onto Chit_Sp was not detected using this technique, since no significant difference was observed between the Chit_Sp film thickness before and after peptide immobilization (Chit_Sp_hLF). This can be explained by the flexibility of the spacer, which can result in a closer positioning of the peptide towards the chitosan film or due to the SS bond formation between the $\mathrm{SH}$ terminal of the $\mathrm{Sp}$. The small increase from $14.6 \pm 1.4 \mathrm{~nm}$ to $17.1 \pm 0.4 \mathrm{~nm}$ observed in chitosan films after immersion in the peptide solution indicates that some hLF1-11 can be adsorbed or incorporated onto chitosan films $(p<0.05)$. No significant thickness difference was observed between chitosan solely incubated with EDC/NHS reagents and Chit_NAC. This situation can be explained by an alternative chemistry pathway where the absence of a carboxylic group allows a direct reaction of the carbodiimide of EDC with the free amine groups of chitosan [33].

\subsubsection{Water contact angle measurements}

Water contact angle of chitosan surfaces before and after chemical modification is shown in Fig. 2B. Chitosan films $\left(\theta_{\mathrm{w}}=64 \pm 2^{\circ}\right)$ became more hydrophilic after NAC and $\mathrm{Sp}$ functionalization $\left(\theta_{\mathrm{w}}=37 \pm 2^{\circ}\right.$ and $49 \pm 1^{\circ}$, respectively) in contrast with the EDC/ NHS modification $\left(\theta_{\mathrm{w}}=58 \pm 1^{\circ}\right)$. After hLF1-11 direct immobilization onto Chit_NAC (Chit_NAC_hLF), the water contact angle increased to $40 \pm 0.1^{\circ}(p<0.05)$, suggesting peptide immobilization onto the polymer. However, surface wettability was not changed, when hLF1-11 was immobilized to Chit_Sp (Chit_Sp_hLF). hLF111 adsorption onto chitosan was also not detected using this technique.

\subsection{3. $A F M$}

Alteration of surface roughness due to the successive chemical modifications on chitosan was analyzed by AFM, as presented in Fig. 2C. AFM allowed the observation of peptide incorporation on both NAC- and Sp-modified chitosan, as the root mean square roughness of Chit_NAC_hLF and Chit_Sp_hLF was respectively $41 \%$ and $64 \%$ higher $(p<0.05)$ than that of the corresponding chitosan modified substrate. No other significant differences were found between the remaining samples.

\subsubsection{IRRAS}

IRRAS spectra of chitosan thin films before and after covalent immobilization of NAC and Sp are shown in Fig. 4.

The spectrum of chitosan immersed in buffer (Chit_b) allows the identification of the characteristic absorption bands of chitosan, as described elsewhere [25,26,34-36]. After reaction with NAC and Sp, the increase of the characteristic amide I IR absorption $\left(1660 \mathrm{~cm}^{-1}\right)$ confirms the covalent reaction between chitosan free amine groups and the terminal carboxylic groups of NAC or Sp. Chitosan incubated with EDC/NHS reagents also presented a similar peak augmentation (data not shown) in the same region, which is consistent with the mentioned alternative chemical pathway (on Fig. 3) involving the formation of an imine intermediate $(\mathrm{C}=\mathrm{N}$ stretching typically ranges from 1690 to $1630 \mathrm{~cm}^{-1}$ ) [37]. The C$\mathrm{H}$ stretching peak at $2876 \mathrm{~cm}^{-1}$ was masked on the Chit_NAC and Chit_NAC_hLF samples, but it was slightly increased in the Chit_Sp sample, as expected from the seven ethylene units from the polyethylene (PEG) spacer. Sp-modified samples have also shown a slightly deviated peak, from $1080 \mathrm{~cm}^{-1}$ to $1114 \mathrm{~cm}^{-1}$, attributed to $\mathrm{C}-\mathrm{O}-\mathrm{C}$ stretching vibration on a straight chain (of the spacer) instead of a glucopyranose ring (of chitosan). Spectra from chitosan thin films obtained after hLF1-11 adsorption or immobilization are shown in Fig. 4. In all cases, hLF1-11 peptide could be detected through an increase of the amide I peak $\left(1660 \mathrm{~cm}^{-1}\right)$ characteristic of peptides/proteins. However, chitosan 

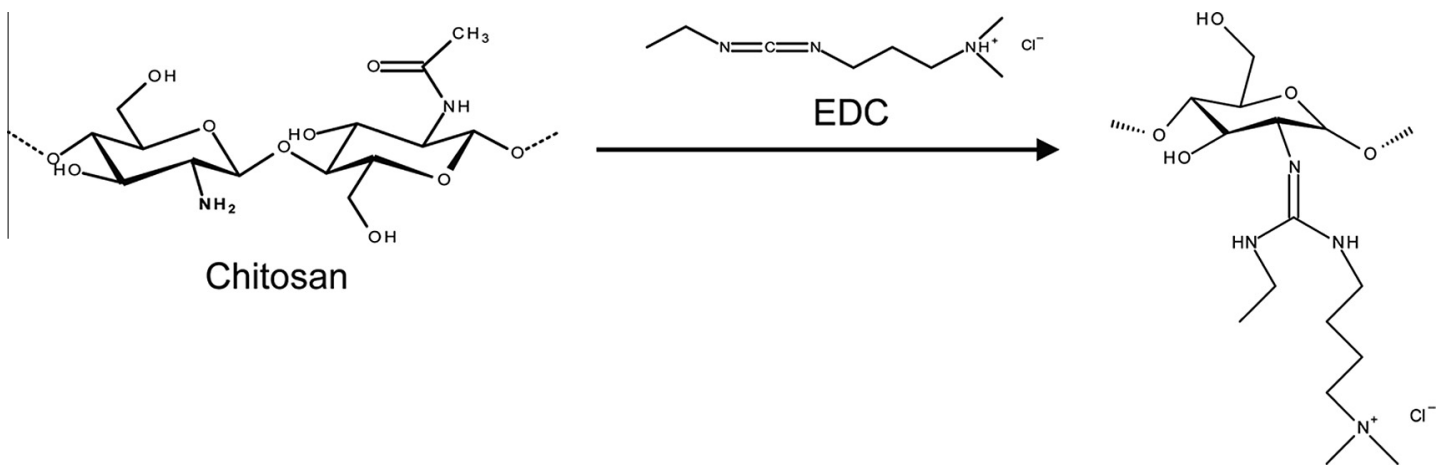

Fig. 3. Reaction of carbodiimide (EDC) and NHS with chitosan free amines.

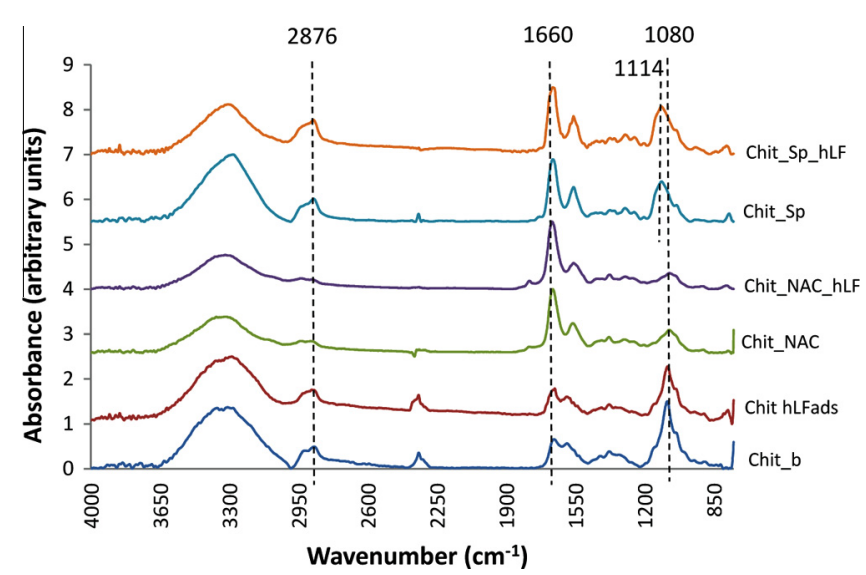

Fig. 4. IRRAS spectra of chitosan modified films and hLF1-11 immobilized chitosan films.

films modified either with NAC or with Sp also display this absorption band. Therefore, to assess hLF1-11 immobilization, a peak height ratio (amide I peak height $\left(1660 \mathrm{~cm}^{-1}\right) / \mathrm{C}-\mathrm{O}-\mathrm{C}$ peak height $\left.\left(1080 \mathrm{~cm}^{-1}\right)\right)$ was calculated for NAC-derived samples, since Sp samples have signal overlap at the $1080 \mathrm{~cm}^{-1}$ band. A higher peak ratio was found on immobilized peptide samples (4.62) than on the NAC samples (2.71), suggesting peptide immobilization. The slight decrease in the $\mathrm{C}-\mathrm{O}-\mathrm{C}$ vibration peak $\left(1080 \mathrm{~cm}^{-1}\right)$ of chitosan films (Chit_b) after immersion in the hLF1-11 solution (Chit hLFads) also demonstrated that some hLF1-11 was adsorbed or incorporated onto chitosan.

\subsubsection{XPS}

XPS survey spectra demonstrated the absence of contaminants on the films, since no other elements than the expected ones were detected (data not shown). The relative atomic composition of chitosan films (Chit_b) is in accordance with previous reports $[26,36]$. XPS S2p high-resolution spectra were used to detect chemical modifications, since immobilization reactions were performed using sulfur bonds. Table 1 shows the percentage of $S 2 p$ involved in the different chemical bonds, free thiol groups $(\sim 163 \mathrm{eV})$, disulfide (164-165 eV) and oxidized sulfur species (168-169 eV). S2p was only detected on covalently modified chitosan films. Peptide immobilization was confirmed by the increase in the total sulfur percentage with regard to the controls (Chit_NAC and Chit_Sp), specifically the sulfur assigned to the establishment of the disulfide bridge (164-165 eV). However, some disulfide bonds were also observed on the Chit_Sp sample, which can be explained by the flexibility and mobility of the SH-terminated spacer chains. Adsorbed hLF was not detected using this technique, since no sulfur was observed on the Chit_hLFads sample. With the exception of
Chit_NAC_hLF, some oxidized sulfur was always found, due to its exposition on the surface.

\subsubsection{Peptide fluorimetric quantification}

A fluorimetric technique was used to assess hLF1-11 surface density: Chit_NAC_hLF $6.4( \pm 1.4) \mathrm{ng} \mathrm{mm}^{-2}$, Chit_Sp_hLF 4.9 $( \pm 0.8) \mathrm{ng} \mathrm{mm}^{-2}$ and Chit hLF ads $3.7( \pm 1.0) \mathrm{ng} \mathrm{mm}^{-2}$. These results present the same tendency observed on the other characterization techniques, although no statistically significant differences were observed between samples.

\subsection{Antimicrobial activity characterization}

The MIC of the soluble hLF1-11 was $64 \mu \mathrm{g} \mathrm{ml}^{-1}$ for the tested $S$. aureus strain.

Fig. 5A shows the non-adherent viable bacteria (supernatant) after contact for $4 \mathrm{~h}$ with the different surfaces. No significant differences were found between the CFUs of the supernatants of wells with and without samples, except for the gold surface (blank) where a decrease in the number of viable bacteria was observed. Comparing between samples, the number of CFUs on the supernatant of the gold surface was only significantly different from Chit_Sp.

Fig. 5B shows that a thin film of chitosan decreases bacterial adhesion to the gold surface (blank). In contrast, the presence of hLF1-11 induced bacterial adhesion to chitosan, particularly when the peptide was directly immobilized on chitosan (Chit_NAC_hLF) (46-fold higher $(p<0.05)$ ). When analyzing the viable adhered bacteria (Fig. 5C), hLF1-11 incorporation only increased significantly the number of viable bacteria onto chitosan films when the peptide was physically adsorbed onto the surface (Chit hLFads) or immobilized through NAC (Chit_NAC_hLF) $(p<0.05)$. However, although bacteria adhesion on Chit_NAC_hLF was $\sim 1.7$ times higher than on the blank surface, the number of viable adherent bacteria between these two surfaces was similar. When hLF1-11 immobilization occurred through a PEG spacer (Chit_Sp_hLF), it was possible to observe a similar surface coverage (Fig. 5B) but a much lower number of viable bacteria $(\sim 80 \%)$ than the blank $(p<0.05)$ (Fig. 5C).

Fig. 6 shows one representative image of the adherent bacteria on each sample. Bacteria adhesion was uniformly distributed when hLF1-11 was physically adsorbed onto chitosan film. However, when covalently immobilized, adherent bacteria appeared clumped together.

These results demonstrated that immobilization of hLF1-11 by its cysteine residue leads to a loss of activity. However, hLF1-11 was still able to attract and bind $S$. aureus and kill about half of adherent bacteria, particularly when immobilized through a spacer. 
Table 1

S2p relative surface atomic composition of different chitosan samples.

\begin{tabular}{|c|c|c|c|c|}
\hline \multirow{2}{*}{$\begin{array}{l}\text { Chitosan } \\
\text { samples }\end{array}$} & \multirow[t]{2}{*}{$\mathrm{S} 2 p(\%)$} & \multicolumn{3}{|l|}{ S2p (at.\%) } \\
\hline & & $\sim 163$ eV S-H & $164-165$ eV S-S & $168-169 \mathrm{eV} \mathrm{SO}_{3}$ \\
\hline Chit_b & 0 & 0 & 0 & 0 \\
\hline $\begin{array}{c}\text { Chit_EDC/ } \\
\text { NHS }\end{array}$ & 0 & 0 & 0 & 0 \\
\hline Chit_NAC & 0.8 & 67 & 0 & 33 \\
\hline Chit_NAC_hLF & 1.7 & 18 & 82 & 0 \\
\hline Chit_Sp & 0.9 & 33 & 56 & 11 \\
\hline Chit_Sp_hLF & 1.7 & 18 & 64 & 18 \\
\hline Chit hLFads & 0 & 0 & 0 & 0 \\
\hline
\end{tabular}

\section{Discussion}

In this study, different immobilization parameters (orientation and exposition) were assessed in the covalent immobilization of the hLF1-11 peptide onto chitosan ultrathin films. C-terminal immobilization was chosen to orient the arginine-rich portion of the peptide (associated with the antimicrobial activity [6,7,21]) towards the exterior. Also, two exposition levels (direct link and through a spacer) were tested, in order to assess the best immobilization profile for this particular AMP. Surface characterization using a number of different techniques - ellipsometry, IRRAS, XPS, water contact angle measurements, AFM and fluorimetric

(A)
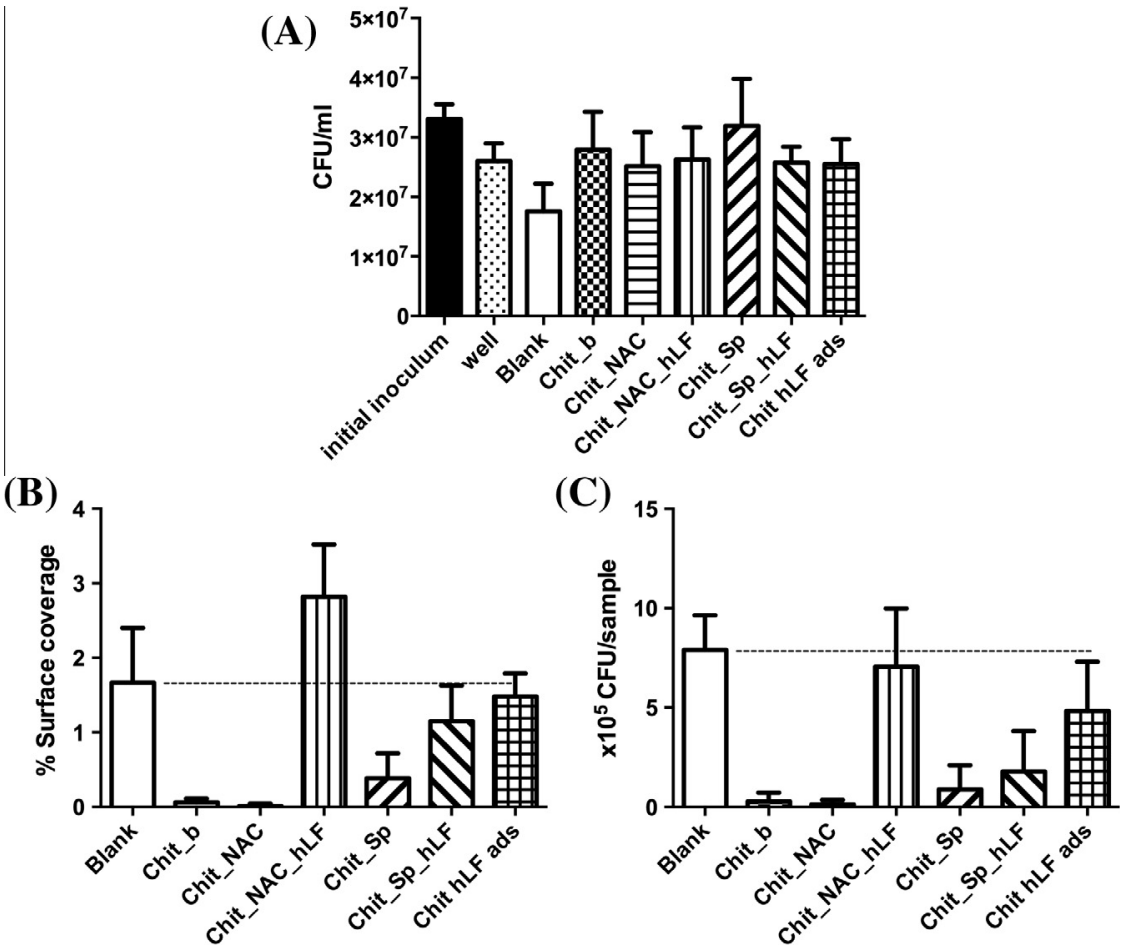

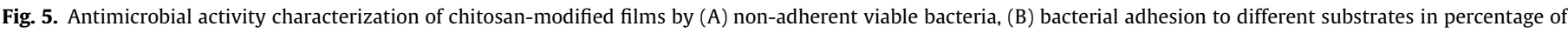
surface coverage, and (C) viable adherent bacteria on different substrates.

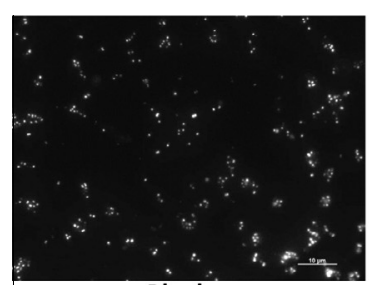

Blank

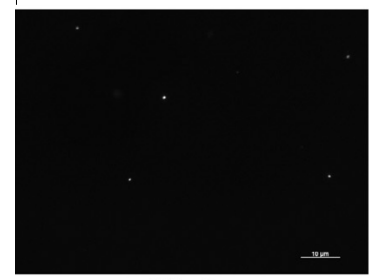

Chit_Sp

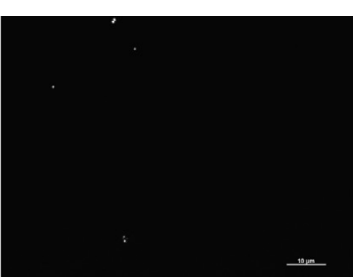

Chit_b

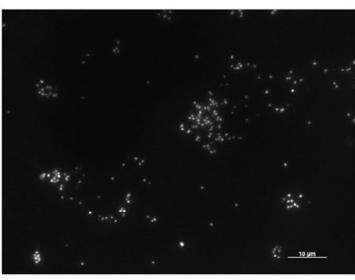

Chit_Sp_hLF

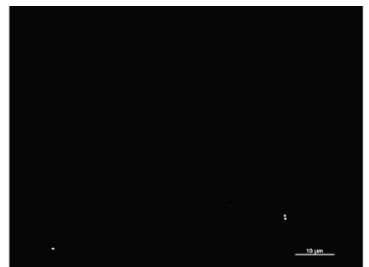

Chit_NAC

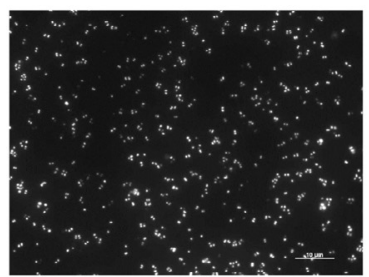

Chit hLF ads

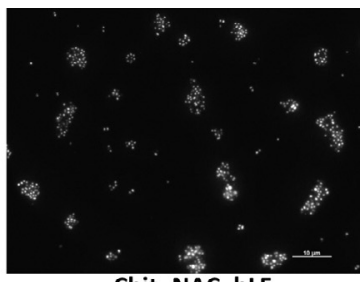

Chit_NAC_hLF

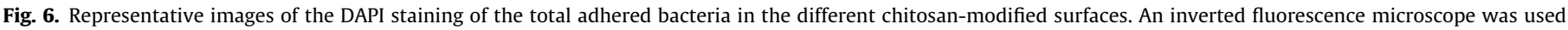
with a magnification of $1000 \times$. Scale bar corresponds to $10 \mu \mathrm{m}$. 
peptide quantification - demonstrated that stable chitosan thin films with and without hLF1-11 was successfully produced. Fluorimetric peptide quantification demonstrated that different chemical approaches allowed the modification of chitosan films with similar amounts of peptide (ranging from 3.7 to $6.4 \mathrm{ng} \mathrm{mm}^{-2}$ ) with different exposure strategies. The covalent immobilization of hLF1-11, either directly or through a spacer, was confirmed by XPS analysis, where the relative content of the S2p peak assigned to the disulfide bridge (164-165 eV) was clearly increased. Moreover, ellipsometry, AFM and contact angle measurements offered further support to peptide immobilization. Higher thickness and roughness were consistently observed on surfaces with peptide covalently immobilized, as well as an altered wettability congruent with the chemical modification promoted. Direct hLF1-11 immobilization (Chit_NAC_hLF) was also confirmed by IRRAS due to the rise of the characteristic infrared absorption bands of proteins, in particular, the amide I band. hLF1-11 physical adsorption onto chitosan films was not detected by water contact angle measurements or XPS analysis (no S2p). However, a slightly thicker film $(17.1 \mathrm{~nm})$ was observed when compared to control chitosan film $(14.6 \mathrm{~nm})$ and the slight decrease on the chitosan $\mathrm{C}-\mathrm{O}-\mathrm{C}$ vibration peak at $1080 \mathrm{~cm}^{-1}$, determined by IRRAS, confirms some peptide adsorption.

Antimicrobial activity of soluble hLF1-11 was firstly tested against ATCC $33591 \mathrm{~S}$. aureus strain, as this species is the most prevalent in implant-related infections [8,38]. This S. aureus strain presented a minimum inhibitory concentration of $64 \mu \mathrm{g} \mathrm{ml}^{-1}$. This value is higher than that reported elsewhere [5,7,21,39]. However, since MIC values determined by different authors were performed under different conditions, namely different incubation times and initial inoculum, MIC values are mostly difficult to compare. During this work, MICs were calculated using the standard conditions described by Wiegand et al. [31].

The non-adherent viable bacteria assay revealed a uniform bacteria concentration over the different surfaces. The exceptions seen were the blank gold surface, and Chit_Sp. The former lower CFU value may be associated with a higher bacterial adhesion onto the surface, and the later higher CFU value may be explained by the non-fouling properties of the PEGylated surface $[40,41]$.

Considering the bacteria adhered to the surfaces, and congruent to previous reports $[13,15]$, bacterial adhesion to chitosan is very low. After chitosan functionalization with NAC and Sp, the values of adhered bacteria remained low. The low bacterial adhesion on Chit_NAC samples can be explained by some oxidation of the cysteine $\mathrm{SH}$ group in $\mathrm{SO}_{4}^{3-}$ that, due to its negative behavior, can be responsible for repulsive forces towards the negatively charged bacterial membranes. It was also reported that NAC has an inhibitory effect on the slime formation by Staphylococcus epidermis during biofilm formation [42]. Further studies regarding the effect of NAC functionalized chitosan films on bacterial biofilm formation are currently being performed in our laboratory. Chit_Sp has a PEGylated surface, which is well known for its non-fouling properties (i.e. it prevents cell (bacterial or mammalian) adhesion) $[40,41]$. The incorporation of hLF1-11 onto chitosan films was able to attract and bind bacteria, as expected by the orientation chosen for covalent immobilization (exposing the arginine/positive end). The highest value of adherent bacteria on surfaces where hLF111 was directly immobilized could be related to a more rigid exposition of the arginine portion of the peptide. In the particular cases of Chit_Sp_hLF and Chit hLF ads, the enhancement of bacterial adherence is less pronounced, which may be associated with a more flexible (chit_Sp_hLF) or more random (Chit hLF ads) exposition/orientation of the peptide. Nevertheless, when comparing the bacterial surface coverage with the adhered viable bacteria, it is possible to observe that, besides attracting bacteria, the peptide maintains some antimicrobial activity, which is more evident in the spacer modified sample (similar surface coverage with regard to blank but a much lower number of viable bacteria $(\sim 80 \%)$ $(p<0.05))$. It remains to elucidate whether a $C$-terminal immobilization without compromising the cysteine residue would have a more significant activity. A number of other studies with immobilized AMPs have approached the issue of AMP exposure [43-49]. For example, Gabriel et al. [44] demonstrated that the LL37 peptide bound to titanium was capable of killing Escherichia coli on contact, only when a PEGylated spacer was used. The authors suggested that the use of a long, flexible PEG spacer provided a parallel peptide orientation and lateral mobility that were required for bactericidal activity. Therefore, considering the parameters analyzed, the immobilization of hLF1-11 through a spacer renders the best profile, as it simultaneously attracts and kills bacteria.

Recently, Hilpert et al. [50] reported that, in opposition to what was expected, immobilized AMPs that expose their hydrophobic termini exhibit higher antimicrobial activity. It was suggested that the hydrophobic residues could interact with the lipophilic portion of the bacterial membrane, becoming embedded into its surface and destabilizing the packing of the phospholipids. It was also described that tryptophan (W) residues in AMPs could be important for their antimicrobial activity [51], as the aromatic hydrocarbon residues are able to position themselves deeper into the lipid portion of the phospholipid bilayer, making the peptide more efficient in disrupting/destabilizing the bacterial cell membrane [6]. Although the exact mechanism of action of hLF1-11 is still not elucidated, the membrane-induced peptide conformation [52] and high speed of action [53] suggest direct membrane disruption. Therefore, considering an $N$-terminal immobilization of hLF1-11, the hydrophobic end of the peptide would be exposed, which could result on enhanced activity. So the hLF1-11 immobilization chapter is not closed and further studies will allow conclusions to be drawn about the hLF1-11 application in its immobilized form. In view of the above, future work will include new immobilization comparing non-cysteine related $C$-terminal with $\mathrm{N}$-terminal orientation through a chemistry that allows a higher yield of immobilized AMP.

\section{Conclusion}

hLF1-11 covalent immobilization was successfully performed using specific orientation through its $C$-terminal cysteine, with and without a PEG spacer in similar amounts. Chitosan thin films by themselves decreased bacterial adhesion. The functionalization with hLF1-11 increases significantly bacterial adhesion to chitosan films, particularly when the peptide was covalently coupled without a PEG spacer. However, when a PEG spacer is used, hLF1-11 maintained part of its activity.

\section{Acknowledgements}

This work was financed by FEDER funds through the Programa Operacional Factores de Competitividade (COMPETE) and by Portuguese funds through FCT (Fundação para a Ciência e a Tecnologia) in the framework of the projects: PTDC/CTM/101484/2008; PEst-C/ SAU/LA0002/2013. Fabíola Costa acknowledges FCT, for the PhD grant SFRH/BD/72471/2010. We acknowledge Manuela Brás from SUIM (INEB) for the AFM studies.

\section{Appendix A. Figures with essential colour discrimination}

Certain figures in this article, particularly Fig. 4, are difficult to interpret in black and white. The full colour images can be found in the on-line version, at http://dx.doi.org/10.1016/j.actbio.2014. 02.028 . 


\section{References}

[1] Zasloff M. Antimicrobial peptides of multicellular organisms. Nature 2002;415:389-95.

[2] Seo MD, Won HS, Kim JH, Mishig-Ochir T, Lee BJ. Antimicrobial peptides for therapeutic applications: a review. Molecules 2012;17:12276-86.

[3] Perron GG, Zasloff M, Bell G. Experimental evolution of resistance to an antimicrobial peptide. Proc Biol Sci 2006;273:251-6.

[4] Costa F, Carvalho IF, Montelaro RC, Gomes P, Martins MC. Covalent immobilization of antimicrobial peptides (AMPs) onto biomaterial surfaces. Acta Biomater 2011;7:1431-40.

[5] Stallmann HP, Faber C, Bronckers AL, de Blieck-Hogervorst JM, Brouwer CP, Amerongen AV, et al. Histatin and lactoferrin derived peptides: antimicrobial properties and effects on mammalian cells. Peptides 2005;26:2355-9.

[6] Gifford JL, Hunter HN, Vogel HJ. Lactoferricin: a lactoferrin-derived peptide with antimicrobial, antiviral, antitumor and immunological properties. Cell Mol Life Sci 2005;62:2588-98.

[7] Lupetti A, Paulusma-Annema A, Welling MM, Senesi S, van Dissel JT, Nibbering $\mathrm{PH}$. Candidacidal activities of human lactoferrin peptides derived from the $\mathrm{N}$ terminus. Antimicrob Agents Chemother 2000;44:3257-63.

[8] Faber C, Stallmann HP, Lyaruu DM, Joosten U, von Eiff C, van Nieuw Amerongen A et al. Comparable efficacies of the antimicrobial peptide human lactoferrin 1-11 and gentamicin in a chronic methicillin-resistant Staphylococcus aureus osteomyelitis model. Antimicrob Agents Chemother 2005;49:2438-44.

[9] van der Does AM, Bogaards SJ, Ravensbergen B, Beekhuizen H, van Dissel JT, Nibbering PH. Antimicrobial peptide hLF1-11 directs granulocyte-macrophage colony-stimulating factor-driven monocyte differentiation toward macrophages with enhanced recognition and clearance of pathogens. Antimicrob. Agents Chemother. 2010;54:811-6.

[10] van der Does AM, Hensbergen PJ, Bogaards SJ, Cansoy M, Deelder AM, van Leeuwen HC, et al. The human lactoferrin-derived peptide hLF1-11 exerts immunomodulatory effects by specific inhibition of myeloperoxidase activity. J Immunol 2012;188:5012-9.

[11] Stallmann HP, de Roo R, Faber C, Amerongen AV, Wuisman PI. In vivo release of the antimicrobial peptide hLF1-11 from calcium phosphate cement. J Orthop Res 2008;26:531-8.

[12] Kazemzadeh-Narbat M, Kindrachuk J, Duan K, Jenssen H, Hancock RE, Wang R. Antimicrobial peptides on calcium phosphate-coated titanium for the prevention of implant-associated infections. Biomaterials 2010;31:9519-26.

[13] Kong M, Chen XG, Xing K, Park HJ. Antimicrobial properties of chitosan and mode of action: a state of the art review. Int J Food Microbiol 2010;144:51-63.

[14] Shi Z, Neoh KG, Kang ET, Poh C, Wang W. Bacterial adhesion and osteoblast function on titanium with surface-grafted chitosan and immobilized RGD peptide. J Biomed Mater Res A 2008;86:865-72.

[15] Carlson RP, Taffs R, Davison WM, Stewart PS. Anti-biofilm properties of chitosan-coated surfaces. J Biomater Sci Polym Ed 2008;19:1035-46.

[16] Hu X, Neoh KG, Shi Z, Kang ET, Poh C, Wang W. An in vitro assessment of titanium functionalized with polysaccharides conjugated with vascular endothelial growth factor for enhanced osseointegration and inhibition of bacterial adhesion. Biomaterials 2010;31:8854-63.

[17] Moutzouri AG, Athanassiou GM. Attachment, spreading, and adhesion strength of human bone marrow cells on chitosan. Ann Biomed Eng 2011:39:730-41.

[18] Kawai T, Yamada T, Yasukawa A, Koyama Y, Muneta T, Takakuda K. Biological fixation of fibrous materials to bone using chitin/chitosan as a bone formation accelerator. J Biomed Mater Res B Appl Biomater 2009;88:264-70.

[19] Lieder R, Darai M, Thor MB, Ng CH, Einarsson JM, Gudmundsson S, et al. In vitro bioactivity of different degree of deacetylation chitosan, a potential coating material for titanium implants. J Biomed Mater Res A 2012;100:3392-9.

[20] Bumgardner JD, Chesnutt BM, Yuan Y, Yang Y, Appleford M, Oh S, et al. The integration of chitosan-coated titanium in bone: an in vivo study in rabbits. Implant Dent 2007;16:66-79.

[21] Nibbering PH, Ravensbergen E, Welling MM, van Berkel LA, van Berkel PH, Pauwels EK, et al. Human lactoferrin and peptides derived from its $\mathrm{N}$ terminus are highly effective against infections with antibiotic-resistant bacteria. Infect Immun 2001;69:1469-76.

[22] Fields GB, Noble RL. Solid phase peptide synthesis utilizing 9fluorenylmethoxycarbonyl amino acids. Int J Pept Protein Res 1990;35: $161-214$.

[23] Collins JM, Leadbeater NE. Microwave energy: a versatile tool for the biosciences. Org Biomol Chem 2007;5:1141-50.

[25] Oliveira JR, Martins MCL, Mafra L, Comes P. Synthesis of an O-alkynyl-chitosan and its chemoselective conjugation with a PEG-like amino-azide through click chemistry. Carbohydr Polym 2012;87:240-9.

[26] Nogueira F, Goncalves IC, Martins MC. Effect of gastric environment on Helicobacter pylori adhesion to a mucoadhesive polymer. Acta Biomater 2013;9(2):5208-15.
[27] Lundin M, Macakova L, Dedinaite A, Claesson P. Interactions between chitosan and SDS at a low-charged silica substrate compared to interactions in the bulk - the effect of ionic strength. Langmuir 2008;24:3814-27.

[28] Castner DG, Hinds K, Grainger DW. X-ray photoelectron spectroscopy sulfur 2p study of organic thiol and disulfide binding interactions with gold surfaces. Langmuir 1996;12:5083-6.

[29] Martins MC, Ratner BD, Barbosa MA. Protein adsorption on mixtures of hydroxyl- and methyl-terminated alkanethiols self-assembled monolayers. J Biomed Mater Res A 2003;67:158-71.

[30] Smith RE, MacQuarrie R. A sensitive fluorometric method for the determination of arginine using 9,10-phenanthrenequinone. Anal Biochem 1978;90:246-55.

[31] Wiegand I, Hilpert K, Hancock REW. Agar and broth dilution methods to determine the minimal inhibitory concentration (MIC) of antimicrobial substances. Nat Protoc 2008;3:163-75.

[33] Dent A, Aslam M. The preparation of protein-small molecule conjugates. In: Dent A, Aslam M, editors. Bioconjugation: protein coupling techniques for the biomedical sciences. London: Macmillan Reference; 1998. p. 368-75.

[34] Osman Z, Arof AK. FTIR studies of chitosan acetate based polymer electrolytes. Electrochim Acta 2003;48:993-9.

[35] Lawrie G, Keen I, Drew B, Chandler-Temple A, Rintoul L, Fredericks P, et al. Interactions between alginate and chitosan biopolymers characterized using FTIR and XPS. Biomacromolecules 2007;8:2533-41.

[36] Amaral IF, Granja PL, Barbosa MA. Chemical modification of chitosan by phosphorylation: an XPS, FT-IR and SEM study. J Biomater Sci Polym Ed 2005;16:1575-93.

[37] Socrates G. Infrared and Raman characteristic group frequencies: tables and charts. 3rd ed. Chichester: John Wiley \& Sons Ltd; 2001.

[38] Toms AD, Davidson D, Masri BA, Duncan CP. The management of periprosthetic infection in total joint arthroplasty. J Bone Joint Surg $\mathrm{Br}$ 2006;88:149-55.

[39] Brouwer CP, Rahman M, Welling MM. Discovery and development of a synthetic peptide derived from lactoferrin for clinical use. Peptides 2011;32:1953-63.

[40] Tsai WB, Chen YH, Chien HW. Collaborative cell-resistant properties of polyelectrolyte multilayer films and surface PEGylation on reducing cell adhesion to cytophilic surfaces. J Biomater Sci Polym Ed 2009;20:1611-28.

[41] Lee Y, Park KM, Bae JW, Park KD. Facile surface PEGylation via tyrosinasecatalyzed oxidative reaction for the preparation of non-fouling surfaces. Colloids Surf B Biointerfaces 2013:102:585-9.

[42] Perez-Giraldo C, Rodriguez-Benito A, Moran FJ, Hurtado C, Blanco MT, GomezGarcia AC. Influence of N-acetylcysteine on the formation of biofilm by Staphylococcus epidermidis. J Antimicrob Chemother 1997;39:643-6.

[43] Haynie SL, Crum GA, Doele BA. Antimicrobial activities of amphiphilic peptides covalently bonded to a water-insoluble resin. Antimicrob Agents Chemother 1995;39:301-7.

[44] Gabriel M, Nazmi K, Veerman EC, Nieuw Amerongen AV, Zentner A. Preparation of LL-37-grafted titanium surfaces with bactericidal activity. Bioconjug Chem 2006;17:548-50.

[45] Steven MD, Hotchkiss JH. Covalent immobilization of an antimicrobial peptide on poly(ethylene) film. J Appl Polym Sci 2008;110:2665-70.

[46] Bagheri M, Beyermann M, Dathe M. Immobilization reduces the activity of surface-bound cationic antimicrobial peptides with no influence upon the activity spectrum. Antimicrob Agents Chemother 2009;53:1132-41.

[47] Gao GZ, Lange D, Hilpert K, Kindrachuk J, Zou YQ Cheng JTJ, et al. The biocompatibility and biofilm resistance of implant coatings based on hydrophilic polymer brushes conjugated with antimicrobial peptides. Biomaterials 2011;32:3899-909.

[48] Glinel K, Jonas AM, Jouenne T, Leprince J, Galas L, Huck WT. Antibacterial and antifouling polymer brushes incorporating antimicrobial peptide. Bioconjug Chem 2009;20:71-7.

[49] Peyre J, Humblot V, Methivier C, Berjeaud JM, Pradier CM. Co-grafting of amino-poly(ethylene glycol) and Magainin I on a $\mathrm{TiO}_{2}$ surface: tests of antifouling and antibacterial activities. J Phys Chem B 2012;116:13839-47.

[50] Hilpert K, Elliott M, Jenssen H, Kindrachuk J, Fjell CD, Korner J, et al. Screening and characterization of surface-tethered cationic peptides for antimicrobial activity. Chem Biol 2009;16:58-69.

[51] Lizzi AR, Carnicelli V, Clarkson MM, Di Giulio A, Oratore A. Lactoferrin derived peptides: mechanisms of action and their perspectives as antimicrobial and antitumoral agents. Mini Rev Med Chem 2009;9:687-95.

[52] Fornili SL, Pizzi R, Rebeccani D. Conformational analysis of a synthetic antimicrobial peptide in water and membrane-mimicking solvents: a molecular dynamics simulation study. Int J Pept Res Ther 2010;16:223-31.

[53] Dijkshoorn L, Brouwer CP, Bogaards SJ, Nemec A, van den Broek PJ, Nibbering $\mathrm{PH}$. The synthetic N-terminal peptide of human lactoferrin, $\operatorname{hLF}(1-11)$, is highly effective against experimental infection caused by multidrug-resistant Acinetobacter baumannii. Antimicrob Agents Chemother 2004;48:4919-21. 